\title{
Dialogis historikalitas dalam memahami teks Soeharto di era demokrasi
}

\section{Historical dialogue in understanding Soeharto's texts in the era of democracy}

\author{
Zamrud Kondang Darajati \\ Departemen Sosiologi, Fakultas Ilmu Sosial dan Ilmu Politik, Universitas Airlangga \\ Surabaya, 60286, Jawa Timur, Indonesia \\ E-mail: zamrud.kondang-13@ fisip.unair.ac.id
}

\begin{abstract}
Abstrak
Belakangan ini terjadi fenomena masyarakat rindu Soeharto. Salah satu gaya kerinduan itu adalah ditemukan sejumlah lukisan mural berisi kritikan halus tapi tajam namun bergenre menghibur tentang seorang Soeharto yang beredar di publik. Teks Soeharto itu, yakni teks Soeharto yang berbunyi "Piye Kabare Bro...?, Penak Jamanku To Le...?". Teks ini ditemukan pada stiker atau gambar dibak-bak truk, mobil angkutan umum, mobil angkutan barang atau pick up, baju atau kaos, papan di jalanan, baliho, dan buku. Studi ini menggunakan metode penelitian kualitatif dengan paradigma interpretatif. Studi ini mengupas makna dan opini masyarakat mengenai teks Soeharto yang muncul pada era Demokrasi saat ini dengan bantuan pisau analisis Hermeneutika oleh Hans Georg Gadamer. Hasil penelitian menunjukkan bahwa, fenomena tersebarnya teks Soeharto pada era demokrasi ini dapat dilator belakangi oleh berbagai motif yang mengatasnamakan kerinduan rakyat pada Era Soeharto, yakni: motif ekonomi, motif politik, motif sosial, motif moralitas, motif humor, dan motif iklan (propaganda) berupa pemberitahuan maupun ajakan, motif penunjukan identitas diri dan motivasi kritikan terhadap pemerintahan saat ini untuk kehidupan yang lebih baik. Selain itu terdapat 4 analisis Dialogis Historikalitas Gadamer, diantaranya: Pertama, bildung, yaitu barang-barang yang menggunakan teks Soeharto, bahasa jawa dan bahasa gaul, baju safari, jas hitam dan peci, baju loreng, rokok klobot cigarillos, senapan api. Kedua, sensus communis, yaitu opini masyarakat mengenai tersebarnya teks Soeharto dan makna senyuman, serta lambaian tangan Soeharto. Ketiga, pertimbangan, yaitu makna senyuman Soeharto dan peci. Keempat, selera, yaitu bahasa jawa dan bahasa gaul, baju safari, jas hitam dan peci, baju loreng, serta pandangan positif dan negatif teks Soeharto.
\end{abstract}

Kata kunci: teks Soeharto; Orde Baru; demokrasi; hermeneutika

\begin{abstract}
Lately there has been a phenomenon of the Soeharto people longing. One of the gayindindindindangan is found a number of mural paintings containing subtle but sharp criticism but entertaining genre about a Suharto that circulated in public. Soeharto's text, namely Soeharto's text which reads "Piye Kabare Bro ... ?, Penak Jamanku To Le ...?". This text is found on stickers or pictures in the back of trucks, public transportation cars, freight or pick-up cars, shirts or shirts, boards on the street, billboards, and books. Researchers used qualitative research methods with interpretive paradigms. Researchers want to explore the meaning and public opinion of the Soeharto text that emerged in the current era of Democracy with the help of Hermeneutics analysis knife by Hans Georg Gadamer. The Soeharto era, namely: economic motives, political motives, social motives, morality motives, humor motives, and advertising motives (propaganda) in the form of notices and invitations, motives for self-identification and motivation for criticism of the current government for a better life. In addition, there are 4 Gadamer Historical Dialogical analyzes, including: First bildung, namely items using Suharto texts, Javanese and slang, safari shirts, black suits and caps, camouflage shirts, cigarillos klobot cigarettes, firearms. The two communist censuses, namely public opinion about the spread of Soeharto's text and the meaning of smiles, and the wave of Suharto's hands. The third consideration is the meaning of Soeharto's smile and the cap. And the four tastes, namely Javanese and slang, safari shirts, black suits and cap, striped shirts, as well as positive and negative views of Suharto's text.
\end{abstract}

Keywords: Suharto text; new order; democracy hermeneutics 


\section{Pendahuluan}

Indonesia merindukan sosok Soeharto. Terlepas dari sisi buruk yang pernah dilakukannya, dengan karakter pemerintahannya yang kuat, Soeharto telah berhasil menyejahterakan masyarakatnya dan tentunya masyarakat tidak mudah untuk melupakannya. Terbukti dengan banyaknya teks Soeharto yang beredar di era Demokrasi saat ini dengan berbagai macam bentuk (Purnaweni, 2004; Piliang, et al., 2016; Wadilapa, 2015). Salah satu gaya kerinduan itu adalah ditemukan sejumlah lukisan mural berisi sentilan halus tapi tajam namun bergenre menghibur tentang seorang Soeharto yang beredar di media (Adityawan, 2008). Aneka teks, seperti dalam bentuk mural, grafiti dan lukisan yang memiliki makna tajam sekaligus menghibur itu, yakni teks Soeharto yang berbunyi "Piye Kabare Bro....?, Penak Jamanku To Le...?". Masih banyak lagi lainnya dengan tulisan bernada sama tapi dengan tambahan kata-kata yang sedikit panjang tetapi memiliki makna yang sama, seperti "Piye kabare kepenak jamanku toh?", "Gimana kabare...sih enak jamanku bro?","Pripun kabare kepenak jamanku to le?", "Piye kabare...sek penak jamanku toh?". Seperti stiker atau gambar dibak-bak truk, mobil angkutan umum, mobil angkutan barang atau pick up, baju atau kaos, papan di jalanan, bahkan terdapat baliho yang sangat besar yang bertuliskan “Piye kabare...sek penak jamanku toh?” (“Bagaimana kabarnya...masih enak jamanku toh?”).

Selain itu ditemukan hal yang sangat menarik berkaitan dengan teks Soeharto, yaitu terdapat salah satu rumah makan di Surabaya bagian Barat yang menyuguhkan teks Soeharto sebagai sampul daftar menu makanan. Teks tersebut berbunyi "Piye Kabare? Opo Sik Genah Ripah Loh Jinawi, MURAH SANDANG PANGAN Koyok Jamanku Biyen". Teks Soeharto disuguhkan oleh si pemilik kepada konsumen, pasti memiliki makna yang ditujukan pada konteks tertentu. Bukan hanya itu, ditemukan pula dua buah buku yang bertekskan Soeharto, yang berjudul "Gimana Kabarmu, Nak, Masih Enak Jamanku, Tho?" (Sumartono, 2013) dan "Piye Kabare....? Penak Jamanku to!" (JK et al, 2014), dimana kedua buku tersebut mengulas secara detail tentang seputar kehidupan Soeharto dan mengulas masa kejayaan pemerintahan Soeharto pada masa Orde Baru serta membandingkan keadaan Indonesia pada era Demokrasi saat ini.

Sebuah survei digulirkan oleh lembaga penelitian Indo Barometer. Hasil survei menyebutkan bahwa sebesar 40,9\% responden mempersepsikan bahwa Orde Baru lebih baik dibandingkan dengan Orde Demokrasi yang hanya didukung oleh22,8\% responden. Mungkin saja hasil survei itu kurang akurat, namun setidaknya hal tersebut sebagai bentuk akumulasi kekecewaan publik terhadap pemerintah SBY selama dua periode.

Studi atau kajian yang membahas tentang pemerintahan Orde Baru maupun Soeharto sudah banyak dilakukan. Seperti penelitian yang dilakukan oleh Anderson. Anderson menggunakan perspektif yang sejalan dengan hermeneutika, dan memfokuskan kajiannya pada konsep kekuasaan dalam kosmologi Jawa, Anderson menemukan perbedaan yang mencolok antara konsep kekuasaan dalam tradisi Jawa dan Barat. Berbeda dengan konsep modern tentang kekuasaan, dalam tradisi Jawa kekusaan bersifat homogen, konkret, dan konstan dalam keseluruhan dan tidak berimplikasi moral (Ashrianto, 20016).

Kajian Anderson diteruskan oleh Michael van Langenberg dengan mengindentifikasi 40 kata kunci yang mengekspresikan ideologi Orde Baru di seputar masalah kekuasaan, akumulasi, legitimasi, budaya, dan penentangnya. Wacana yang menginformasikan 40 kata kunci Orde Baru mengartikulasikan suatu bentuk negara yang bersifat otoriter, berketuhanan, berlandaskan hukum, berdasarkan undang-undang dan mengalami perubahan struktural besar-besaran. 
Belakangan kajian mengenai wacana politik Indonesia sudah memperoleh perhatian secara serius dari intelektual Indonesia sendiri seperti Ariel Heryanto mengenai wacana negara dan Daniel T. Sparringa tentang peranan intelektual dalam wacana politik dan demokrasi di Indonesia era Orde Baru. Dengan menggunakan pendekatan behaviorisme, studi Heryanto menemukan bahwa wacana developmentalisme yang dikembangkan oleh rejim Orde Baru yang sangat hegemonik dianggap telah menghancurkan hampir seluruh sendi-sendi dan tatanan kehidupan berbangsa dan bernegara.

Sementara itu, studi Sparringa tentang peranan dan posisi intelektual dalam wacana demokrasi di Indonesia, mengemukakan bahwa secara umum terdapat tiga macam kelompok intelektual di Indonesia, kelompok Ortodok yang mendukung wacana resmi negara, kelompok Revisionis, merupakan kelompok dengan jumlah terbesar, yang mendukung tetapi juga mempertanyakan beberapa persoalan wacana negara, dan kelompok Oposisionis yang terang-terangan menentang wacana resmi negara dengan memberikan wacana alternatif sebagai cara pemecahan masalah. Penelitian membahas tentang diskursus, demokratis, dan intelektual dalam pemerintahan Orde Baru. Menurut Sparringa, Negara Orde Baru mempunyai diskursus-diskursus resmi untuk meletakkan dasar legitimasi, misalnya kata "Demokrasi Pancasila", "Pembangunan", dan "Kesatuan."

Studi dan penelitian di atas tentang masa Pemerintahan Soeharto atau Orde Baru, baik dari sisi politik, wacana, bahasa dan sejarah menjadi berbeda dengan penelitian lain, sebab, secara sosiologis penelitian ini ingin mengupas pemikiran masyarakat tentang pemaknaan masyarakat mengenai teks Soeharto yang beredar di era Demokrasi saat ini. Dengan mengupas pemikiran masyarakat, peneliti ingin menemukan pemaknaan sosial terhadap teks Soeharto.

Studi ini ingin mengupas pemikiran masyarakat tentang pemaknaan sosial mengenai teks Soeharto yang muncul pada era Demokrasi, di mana muncul romantisme era Soeharto dengan bantuan pisau analisis Teori Gadamer tentang hermeneutika. Karena sebuah teks tidak dapat hanya dinilai atau dilihat sebagai medium yang netral untuk penyampaian suatu pesan melalui bahasa tertentu, tetapi teks sebagai proses produksi dan reproduksi suatu konteks sosial, serta tidak pernah lepas dari historis. Sehingga dengan hadirnya teks Soeharto masyarakat dapat mengungkapkan penafsiran atau persepsi atas dirinya terhadap teks Soeharto. Karena teks merupakan media bagi manusia dalam berkomunikasi. Melalui teks, manusia dapat mengungkapkan ide, pikiran, dan perasaannya.

\section{Metode Penelitian}

Studi ini menggunakan metode penelitian kualitatif dengan paradigma interpretif. Analisa data yang digunakan dalam penelitian ini adalah analisis data kualitatif (Moleong, 2012). Setelah data berhasil dikumpulkan kemudian dilakukan reduksi data dan kategorisasi data berdasarkan isu penelitian. Analisis data dilakukan dengan mendialogkan dan mendiskusikan dengan teori dan stud-studi terdahulu yang relevan dengan topik yang dikaji.

Hermeneutika adalah sebuah konsep interpretatif terhadap simbol, tradisi, tindakan, teks, dan bentukbentuk material lainnya yang bersifat konkrit, misalnya ilmu pengetahuan dan teknologi. Pemahaman Gadamer terhadap pendekatan historikalitas adalah proses interpretasi terhadap objek dengan memahami sejarah munculnya objek itu. Menurut Gadamer Interpretasi tanpa menggunakan pendekatan historis akan sangat sulit untuk memahami teks sebagai objek interpretatif. 
Dalam hermeneutika interpretator dituntut untuk aktif menganalisa dan bahkan harus berprasangka terhadap teks interpretatif. Hal ini dilakukan melalui prasangka- prasangka interpretator atas teks interpretatif. Meskipun demikian pijakan akhir hermeneutika atas objek tetap kembali pada kebenaran sejarah yang mempengaruhi kebenaran teks tersebut, bukan penuh dari prasangka interpretator. Hasil analisa tersebut, oleh Gadamer disebut "prasangka legitimate". Bagan uraian sebagaimana Gambar 1.

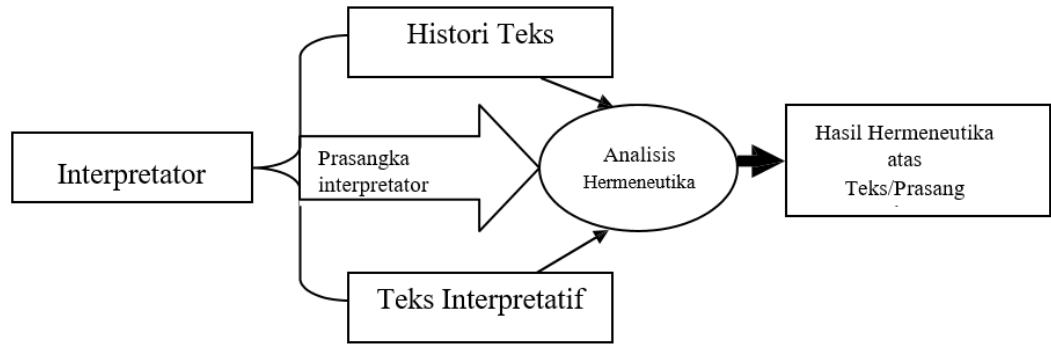

Gambar 1.

Proses hermeneutika historikalitas

Sumber: Penjelasan Josef Bleicher tentang Hermeneutika Gadamer dalam bukunya yang berjudul Hermeneutika Kontemporer, Cetakan 2007

Gambar 1 menjelaskan proses hermeneutika historikalitas Gadamer dalam hermeneutika historis diantaranya sebagai berikut: 1) Interpretator, yaitu subjek hermeneutika, 2) Teks Interpretatif, yaitu objek hermeneutika; 3) Historis tek, yaitu pendekatan metodologis hermeneutika; 4) Prasangka Interpretator, yaitu asumsi bebas interpretator atas teks; 5) Analisa data, yaitu proses reduksi antara teks dan historis teks; dan 6) Prasangka legitimate, yaitu prasangka yang sudah dibuktikan oleh pembenaran historis atas teks.

Hubungan antar elemen di atas bagai hubungan biologis anatomi tubuh, bagian-bagian sistem saling membutuhkan. "Hermeneutika tanpa penjelasan historis tidak akan menemukan hasil objektivitas ilmiah" dan "hermeneutika akan mengalami kematian teks tanpa ada prasangka interpretator".

\section{Hasil dan Pembahasan}

\section{Hermeneutika, proses dialogis dialektis}

Memahami teks adalah proses dialogis antara interpretator dengan teks. Interpretator melakukan komunikasi intensif terhadap teks sebagai objek interpretatif. Interpretator menyampaikan pertanyaanpertanyaan penting terhadap objek. Hanya saja yang perlu diingat, jawaban teks adalah jawaban merupakan hasil kerja interpretator.

Dapat disimpulkan, hubungan interaksi antara interpretator dan objek interpretatif (teks) adalah hubungan dinamis dan dialektis. Dalam hermeneutika, teks bukan lagi benda mati seperti yang kita pahami, tapi jauh dari itu, ia menyampaikan argumen-argumen ilmiah (ilmiah perspektif teks) untuk dipertahankan dan dipertanggungjawabkan terhadap interpretator atau pembaca. Interpretator tentu memiliki peran yang sama, yaitu mempertanyakan kebenaran teks dengan berbagai proposisi yang komprehensif, yaitu proposisi historis, makna teks, prasangka legitimate, dan beberapa proposisi lain yang dianggap dapat membongkar makna dibalik teks. 
Menurut Gadamer kunci hermeneutika adalah interpretator dan bahasa (Gadamer, 1975). Interpretasi dan dialogis adalah dua proses yang tidak bisa dilepaskan dari bahasa. Bahasa, dialogis, interpretasi, dan dialektika dalam hermeneutika memiliki hubungan simbiosis mutualisme, yaitu hubungan yang saling mempengaruhi dan mengisi dalam penjelasan hermeneutika. Tujuan akhir dari tiga elemen tersebut adalah mengarahkan teks "mati" menjadi teks "hidup", yaitu teks komunikatif. Teks komunikatif adalah tujuan utama hermeneutika dalam mencari kebenaran objektif. Dalam hermeneutika kebenaran objektif yang dimaksudkan bukan kebenaran absolut aksiomatik tapi kebenaran yang memberikan ruang bagi siapapun untuk mengkoreksi, mengkritisi, meneliti, dan mendebatkannya.

Bagi Gadamer esensi kebenaran adalah relatif, yaitu tergantung bagaimana orang menafsirkannya, dan dalam konteks mana teks itu muncul. Kebenaran teks adalah kebenaran kontekstualitas bukan universalisisme seperti kaum positivistik memahaminya. Oleh karena itu, Gadamer mewajibkan kepada siapun, jika ingin memahami teks maka pahamilah sejarah munculnya teks itu. Inilah kunci utama Gadamer dalam ilmu hermeneutika.

Dalam memahami sebuah teks, Hermeneutika Gadamerian memberikan definisi berbeda tentang makna. Makna dalam Hermeneutika Gadamerian bukan terletak pada instensi prosedurnya, melainkan pembacanya itu sendiri (Davey, 2012). Hermeneutika tidak menyingkap makna objektif yang dikehendaki pengarangnya, tetapi adalah untuk memproduksi makna yang seluruhnya memusat pada kondisi historitas dan sosialitas pembaca.

\section{Dialogis historikalitas dalam memahami teks Soeharto}

Menurut Gadamer, tujuan hermeneutika bukanlah menerapkan berbagai macam aturan baku dan kaku untuk meraih pemahaman yang "benar objektif", tetapi untuk mendapatkan pemahaman seluas mungkin. Dalam proses pemahaman dan interpretasi dengan sistem dialektika ini, Gadamer meniscayakan empat faktor yang tidak boleh diabaikan. Pertama, bildung atau pembentukan jalan pikiran. Kedua, Sensus Communis atau pertimbangan praktis yang baik atau pandangan yang mendasari komunitas. Ketiga, pertimbangan, yaitu menggolongkan hal-hal yang khusus atas dasar pandangan tentang yang universal. Keempat, taste atau selera, yaitu sikap subjektif yang berhubungan dengan macam-macam rasa atau keseimbangan antara insting panca inderadan kebebasan intelektual. Teori Hermeneutika oleh Gadamer mengenai pemahaman atau interpretasi mengenai teks dengan hubungan antarmakna dalam sebuah teks, serta pemahaman tentang realitas yang hangat perbincangkan yaitu teks Soeharto merupakan dinamika perpaduan berbagai macam faktor dalam sebuah bahasa yang dapat digunakan untuk mengkaji makna dalam setiap simbol yang ada dalam teks Soeharto tersebut sebagaimana ditunjukkan Tabel 1.

Bildung adalah konsep-konsep yang meliputi seni, sejarah weltanschauung (pandangan dunia), pengalaman, ketajaman pikiran, dunia eksternal, kebatinan, ekspresi atau ungkapan, style atau gaya dan simbol, yang kesemuanya itu kita mengerti saat ini sebagai istilah-istilah dalam sejarah. Dalam teks Soeharto, ada beberapa makna dalam simbol yang erat kaitannya dengan bildung, antara lain; Pertama, barang-barang yang tekskan Soeharto. Dalam teks Soeharto terdapat berbagai macam barang yang bersimbol Soeharto, seperti stiker, buku, baliho, kaos dan mug (gelas), barang-barang tersebut memiliki nilai seni dan simbol sejarah pada Orde Baru. Simbol- simbol yang terdapat pada barang-barang tersebut secara otomatis mengandung sebuah kejayaan pada Orde Baru. 
Tabel 1.

Teori Hermeneutika Gadamer

\begin{tabular}{|c|c|}
\hline $\begin{array}{l}4 \text { Analisis Dialogis } \\
\text { Historikalitas }\end{array}$ & Konsep \\
\hline Bildung & $\begin{array}{l}\text { - } \text { Barang-barang yang bertekskan Soeharto } \\
\text { - } \quad \text { Bahasa Jawa dan Bahasa Gaul } \\
\text { - } \text { Baju Safari } \\
\text { - } \quad \text { Jas Hitam dan Peci } \\
\text { - } \quad \text { Baju Loreng } \\
\text { - } \quad \text { Senok klobot / Cigarillos } \\
\text { - }\end{array}$ \\
\hline Sensus Communis & $\begin{array}{l}\text { - Opini masyarakat mengenai tersebarnya teks } \\
\text { Soeharto }\end{array}$ \\
\hline Pertimbangan & $\begin{array}{l}\text { - Makna senyuman Soeharto } \\
\text { - Peci }\end{array}$ \\
\hline Taste / Selera & $\begin{array}{ll}\text { - } & \text { Bahasa Jawa dan Bahasa Gaul } \\
\text { - } & \text { Baju Safari } \\
\text { - } & \text { Jas Hitam dan Peci } \\
\text { - } & \text { Baju Loreng } \\
\text { - } & \text { Pandangan positif dan negatif mengenai teks } \\
& \text { Soeharto }\end{array}$ \\
\hline
\end{tabular}

Kedua, bahasa Jawa dan bahasa Gaul. Dalam teks Soeharto menggunakan kata dengan bahasa Jawa yang digabung bahasa gaul anak muda sekarang, menunjukkan si pembuat hendak membangkitkan Soeharto untuk menghadapi situasi sekarang. Kalimat "piye kabare" juga "piye kabare le" menurut peneliti dibentuk untuk menghadirkan sosok Soeharto yang seakan-akan sudah akrab dan dekat dengan masyarakat. Sapaan tersebut dalam pergaulan masyarakat Yogyakarta juga sering digunakan untuk menunjukkan kedekatan emosional antara sesama kawan (Widjojo \& Noorsalim, 2004). Kedekatan tersebutlah yang ingin dicapai dengan teks tersebut. Apalagi penambahan kata "le" secara eksplisit mengkonstruksikan sosok Soeharto sebagai seorang bapak. Dalam budaya Jawa yang sangat patriarkis, sosok bapak adalah segalanya. Sosok ini dipandang sebagai representasi kekuasaan, pengayom, dan karakter lain yang menunjukkan superioritas seorang patriarki.

Ketiga, baju Safari. Dalam teks Soeharto terdapat salah satu gambar Soeharto yang mengenakan baju Safari. Dalam Kamus Besar Bahasa Indonesia (KBBI), baju safari memiliki makna baju (pria) model jas berlengan pendek, bersaku empat, dibuat dari bahan yang tebal (dril, katun). Namun baju safari memiliki makna tersendiri dalam teks Soeharto. Pada peralihan Orde Lama ke Orde Baru, pilihan berbusana sipil berlanjut propaganda pembangunan melalui busana safari. Soeharto mengenakan safari, diteladani oleh para pejabat dan pengusaha Orde Baru. James Danandjaja (2005) menjelaskan bahwa para pegawai berkedudukan tinggi harus mengenakan setelan safari dengan lencana Korpri di dada. Safari menjadi seragam kerja harian. Presiden dan para Menteri memasang lencana terbuat dari emas, pembeda dari pejabat-pejabat bawahan. Hal ini melambangkan bahwa baju safari merupakan lambang kekuasaan, jabatan, serta status anggota dewan. Istilah "Bapak-bapak berbaju safari" dulu sungguh merupakan kehormatan, karena baju safari bermakna pakaian kehormatan seorang pejabat, baju safari merupakan baju resmi seorang pejabat Negara. 
Keempat, jas hitam dengan peci. Dalam teks Soeharto terdapat salah satu gambar Soeharto yang mengenakan jas hitam dengan peci. Dalam Kamus Besar Bahasa Indonesia (KBBI), makna dari jas hitam adalah baju resmi (potongan Eropa) berlengan panjang, berkancing satu sampai tiga, dipakai di luar kemeja. Dan makna dari peci adalah penutup kepala terbuat dari kain dsb, berbentuk meruncing kedua ujungnya; kopiah; songkok. Dalam kaitannya denga teks Soeharto, jas hitam dengan peci memiliki makna tersendiri. Jika dilihat dari historinya, pada peralihan kekuasaan Orde Lama ke Orde Baru menimbulkan gejolak selera busana. Pada saat itu Soeharto mulai memiliki pertimbangan-pertimbangan politis untuk tampil sebagai penguasa dengan pesona dan kharisma berbeda dari Soekarno. Kebiasaan mengenakan busana militer tak mungkin terus ditampilkan dalam jagat politik sipil. Soeharto mesti membentuk ideimajinasi Orde Baru bereferensi busana. Adegan dramatis berlangsung pada Sidang MPRS 1968. OG Roeder (1976) mengisahkan bahwa Soeharto masuk ke ruang sidang mengenakan busana resmi sipil (kemeja putih dan jas) dan berpeci, diiringi para pemimpin MPRS memakai kemeja putih. Di hadapan mereka, ratusan orang di ruang sidang memakai "baju hijau'. Pak Harto mulai menguatkan barisan Orde Baru, meninggalkan simbol dan memori Orde Lama. Dalam hal ini jas hitam dapat melambangkan orang terpandang dan priyai. Sedangkan peci dapat melambangkan penguasa dengan pesona dan kharisma, kemurahan hati, kewibawaan, alim, tidak meninggalkan budaya religious.

Kelima, baju Loreng. Dalam teks Soeharto terdapat salah satu gambar Soeharto yang mengenakan baju loreng. Dalam Kamus Besar Bahasa Indonesia (KBBI), makna dari baju loreng adalah seragam resmi tentara. Dalam kaitannya dengan beredarnya teks Soeharto, baju loreng dapat diinterpretasikan sebagai simbol kekuatan pada Orde Baru, yaitu sebuah kekuatan keamanan yang dipegang kendali oleh ABRI. Sehingga baju loreng melambangkan sebuah kekuatan Orde Baru yang ingin dimunculkan pada era Demokrasi.

Keenam, rokok klobot/Cigarillos dan senapan api. Dalam teks Soeharto terdapat salah satu gambar Soeharto yang sedang menghisap rokok klobot atau cigarillos dengan senapan api di tanggannya. Cigarillos merupakan jenis rokok yang sangat mahal saat itu, hanya segelintir orang yang dapat menikmati rokok tersebut. Hal ini melambangkan bahwa orang yang menikmati cigarillos adalah orang yang mapan dan cigarillos melambangkan ketenangan hati dan kemakmuran si penikmat. Sedangkan senapan api dapat di interpretasi sebagai lambang kekuasaan Soeharto pada masa Orde Baru.

\section{Sensus Communis}

Menurut pengertiannya yang mendasar, istilah tersebut adalah pandangan yang mendasari komunitas dan karenanya sangat penting untuk hidup. Hidup dalam suatu komunitas atau kelompok masyarakat memperkembangkan suatu pandangan tentang kebaikan yang benar dan umum. Kaitannya dengan teks Soeharto, tentunya dalam hidup bermasyarakat, pandangan antara orang yang satu dengan yang lain berbeda-beda. Hal ini menimbulkan multitafsir. Dengan adanya multitafsir tersebut tentunya akan sulit mengambil titik temu, jadi diperlukan sebuah kesimpulan atau kesepakatan sebagai titik temu untuk menjelaskan makna atas teks Soeharto.

Dalam Sensus Communis ini, konsep pemikiran tentang opini tersebarnya teks Soeharto di era Demokrasi dijadikan sebagai konvensi atau kesepakatan yang dipakai oleh masyarakat sebagai titik temunya. Makna yang terkandung dalam fenomena beredarnya teks Soeharto ini memiliki interpretasi bahwa masyarakat bukan merindukan Soeharto sebagai presiden dan bukan berupaya menghidupkan kembali orang yang telah meninggal, tetapi rakyat ingin sosok pemimpin seperti Soeharto yang dapat mendengar suara rakyat, 
mengayomi rakyat, membuat rakyat merasa aman, tentram, dan sejahtera. Dan yang paling penting adalah memikirkan rakyat kecil (miskin) dalam setiap kebijakan yang akan dibuatnya.

Senyuman dan lambaian tangan Soeharto pada teks Soeharto memiliki makna yang multitafsir. Pada analisis Sensus Communis ini, pandangan informan yang multitafsir mengenai senyuman dan lambaian tangan Soeharto telah sampai pada sebuah kesimpulan atau kesepakatan yaitu Soeharto memiliki senyuman yang penuh dengan makna tetapi berhubungan dengan adanya teks Soeharto, makna senyuman ini berada pada titik temunya, yaitu senyuman yang menggambarkan kemenangan dan kebahagian sosok Soeharto karena senyuman Soeharto menggambarkan bahwa Orde Baru dapat lebih baik daripada era Demokrasi saat ini. Senyuman dan lambaian tangan tersebut seolah sebagai sapaan sindirian bagi pemerintahan saat ini yang dianggap rakyat kurang berhasil dalam mengemban amanahnya pada rakyat yang menaruh harapan pada pemerintahan untuk dapat hidup sejahtera, aman, dan adil.

\section{Pertimbangan}

Konsep pertimbangan mirip dengan Sensus Communis dan selera. Pertimbangan sifatnya adalah universal, namun bukan berarti berlaku umum. Seperti halnya Sensus Communis yang dianggap sebagai harta universal, kemanusiaan namun juga tidak juga digunakan secara umum. Pertimbangan juga bersifat universal, tetapi hanya sedikit orang saja yang kiranya memilliki hal itu serta mempergunakannya sebagaimana mestinya. Pertimbangan dan Sensus Communis keduanya merupakan interpretasi ilmu-ilmu tentang hidup. Melalui pertimbangan orang dapat memilah-milah macam-macam peristiwa. Gadamer sepakat dengan Immanuel Kant tentang pertimbangan yang dihubungkan dengan pengertian estetis atau nilai estetis. Dalam teks Soeharto, terdapat nilai estetis dari sebuah peci dan senyuman yang dapat menggambarkan sisi lain seseorang (Van Langenberg, 1986). Senyuman Soeharto, berkenaan dengan hal pertimbangan mengenai senyuman Soeharto ini memiliki dua makna, yaitu: senyuman Soeharto dapat bermakna sebuah sapaan kepada rakyatnya dan Senyuman Soeharto juga dapat melambangkan sapaan kepada rakyat miskin dengan adanya sindiran bahwa jaman Soeharto lebih baik daripada sekarang.

Jadi dapat dikatakan bahwa dalam makna yang kedua ini senyuman Soeharto adalah memiliki makna untuk menyapa tetapi juga melambangkan adanya sindiran kepada pemerintahan sekarang atas kinerjanya. Bahwa dalam kesejahteraan rakyat, pemerintahan Orde Baru dapat lebih memberikan angin segar kepada rakyatnya.

Berkaitan dengan peci, beberapa pertimbangan mengenai makna peci yang mengandung nilai estetis yaitu bahwasanya peci adalah sebuah benda untuk menutup kepala dan yang pada umumnya digunakan oleh seorang laki-laki untuk beribadah, yang artinya peci tidak lepas dari budaya religious. Dengan digunakannya peci yang dipasangkan dengan kemeja putih, jas hitam atau baju safari, secara tidak langsung juga dapat menimbulkan keindahan dan melambangkan penguasa dengan pesona dan kharisma kehormatan, kemurahan hati, kewibawaan dan alim. Inilah beberapa pertimbangan estetis dari peci tersebut.

\section{Taste atau selera}

Menurut gadamer orang tentu saja dapat menyukai apa yang orang lain tidak suka. Oleh karena itu tentang selera tidak perlu diperdebatkan, sebab tidak ada kriteria untuk menentukan selera. Menurut Gadamer selera sama dengan rasa, yaitu dalam p engoperasiannya tidak memakai pengetahuan akali. Jika selera menunjukkan reaksi negatif atas sesuatu, kita tidak tahu sebabnya. Tetapi selera tahu pasti tentang hal itu. 
Gadamer mempertentangkan antara selera yang baik dengan yang tidak menimbulkan selera. Gadamer menyatakan bahwa fenomena selera adalah kemampuan intelektual untuk membuat diferensiasi atau pembedaan, tetapi kemampuan ini tidak dapat didemonstrasikan. Selera tidak terbatas pada apa yang indah secara alami dan di dalam seni, tetapi sebaliknya justru meliputi seluruh moralitas dan perilaku atau tabiat. Dalam teks Soeharto, ada beberapa makna yang dapat menunjukkan taste atau selera, antara lain: Pertaman, bahasa Jawa dan bahasa gaul. Dalam teks Soeharto menggunakan bahasa Jawa yang dipadu padankan dengan bahasa gaul. Hal tersebut merupakan pilihan bahasa yang menciptakan teks Soeharto. Penciptanya memilih kedua bahasa tersebut agar mudah diingat karena menggunakan bahasa jawa dan gaul yang simple, serta agar mudah dimengerti pesan dari teks Soeharto tersebut.

Kedua, baju safari. Baju safari merupakan baju dinas untuk pegawai negeri. Sejak awal Orde Baru, baju safari terkenal sebagai baju yang menyimbolkan status sosial seseorang yang patut untuk dihormati. Namun kenyataannya, sekarang banyak yang memiliki dan menggunakan baju safari, baik dari kalangan menengah atas maupun kalangan menengah kebawah. Hal ini dikarenakan beberapa orang dapat memiliki baju safari karena pemberian orang pegawai negeri, adapula yang memang berniat membeli atau menjahitkan dengan model baju safari, hanya saja berbeda warna dan bahan kainnya. Jadi secara tidak langsung, dapat di interpretasikan bahwa baju safari bukan hanya digunakan oleh pegawai negeri, tetapi dapat digunakan oleh semua kalangan masyarakat.

Ketiga, jas hitam dengan peci. Jas hitam dan peci merupakan model baju yang bersejarah ketika awal Orde Baru karena Soeharto yang memikirkan setelan jas hitam dan peci untuk pembeda style busana dengan Orde Lama (Abdulgani-Knapp, 2007). Jas hitam dan peci menyimbolkan kepriyaian seseorang. Karena menggambarkan orang yang berwibawa, disegani, dan memiliki kereligiusan, serta menunjukkan tingkat sosial seseorang. Saat ini banyak masyarakat yang menggunakannya, bukan hanyak dari kalangan elit saja, tetapi semua kalangan untuk menggambarkan sosok seseorang yang memiliki kedudukan di bidang tertentu. Peci tersebut bisa menunjukkan kereligiusan seseorang, ditambah dengan jasnya, terkesan seperti orang yang terhormat.

Keempat, baju loreng secara resmi merupakan motif baju tentara. Tetapi motif loreng juga menjadi trend motif pakaian masyarakat sipil. Motif loreng saat ini bukan hanya sebagai simbol seragam TNI, tetapi menjadi corak pakaian yang disukai semua kalangan, mulai dari anak-anak sampai dewasa, laki-laki dan perempuan. Berbeda ketika Orde Baru, motif itu hanya digunakan oleh anggota TNI. Dulu sempat diperdebatkan, karena seharusnya hanya TNI yang boleh menggunakannya, ada beberapa anggota yang merasa dilecehkan apabila ada orang sipil yang menggunakannya. Tapi semakin kesini, anggota TNI berfikir berarti banyak orang yang menyukainya, mereka jadi bangga karena masyarakat juga ingin menggunakannya. Sekarang banyak toko pakaian yang menjual baju loreng, itu terbukti banyak peminatnya juga. Saat ini bukan berarti yang menggunakan baju loreng itu seorang anggota TNI, tetapi anggota TNI berbangga karena banyak orang yang menyukainya.

Dalam penerapannya dengan makna teks Soeharto ini, terdapat banyak selera yang berbeda antara orang yang satu dengan yang lain. Selera ini muncul akibat adanya beberapa pertimbangan. Dalam teks Soeharto terdapat beberapa pandangan dari masyarakat. Ada dua pandangan yang berbeda mengenai makna beredarnya teks Soeharto ini, yaitu pandangan yang positif dan pandangan negatif.

Beredarnya teks Soeharto ini dapat bermakna positif yaitu untuk mengembalikan rasa aman, tentram dan makmur dari masyarakat, serta dapat menghidupkan kembali sisi-sisi positif dalam pemerintahan Soeharto (Elson, 2001). Namun dari semua sisi baik beredarnya teks Soeharto, kita juga dapat melihat bagaimana 
sisi negatifnya karena pada teks tersebut ada simbol-simbol yang tujukan pada konteks tertentu. Misalnya untuk membangkitkan kuasa militerisme di ranah politik (Benedict, 2007; Holt, 2007; Wardaya, 2007). Jika seperti itu, maka hal itu merupakan suatu bahaya laten bagi kehidupan politik Indonesia, karena bisa saja teks tersebut memiliki makna tersembunyi, yaitu propaganda politik yang menjatuhkan nama pemimpin saat ini (SBY) dan menjunjung tinggi pemimpin masa lalu (Soeharto) dengan nostalgia romantisme kejayaan masa Orde Baru yang berujung pada tujuan-tujuan tertentu untuk kemenangan calon pemimpin pemilu pada tahun 2014 ini. Hal ini dikhawatirkan dapat mengancam semangat era demokrasi karena kembalinya era otoriter seperti pada masa Orde Baru ketika itu.

\section{Makna isi teks Soeharto}

Teks Soeharto memiliki makna yang dalam meskipun terlihat seperti kalimat yang sederhana. Teks Soeharto ditampilkan dengan "Senyum Soeharto" dan wajah sumringah sambil melambaikan tangan. Terdapat tulisan yang memperbandingkan keadaan saat ini dengan kondisi di masa Orde Baru seakan menunjukkan senyum kebanggaanya. Ya, Soeharto bak lahir kembali ke dunia menyapa orang-orang Indonesia yang dahulu telah menghujatnya. Dan rakyat merasakan kerinduan akan sosok Soeharto.

Fenomena tersebarnya teks Soeharto setidaknya menggambarkan representasi suara masyarakat yang sudah jenuh dengan kondisi sosial yang tidak memanusiakannya. Harga-harga melambung tinggi, kekerasan marak terjadi, juga masalah-masalah sosial yang justru semakin parah pasca momentum reformasi. Melalui sosok Soeharto yang "dihidupkan" kembali inilah, suara-suara itu mencoba menerobos kepenatan mereka yang selama ini ditindas oleh keadaan.

Pengangkatan kembali sosok Soeharto sebagai sarana kritik sosial juga tidak terlepas dari pandangan masyarakat pada tokoh tersebut. Soeharto menjadi imajinasi histori masyarakat yang terkungkung pada kesejahteraan masa lalu. Dari hal inilah peneliti berpendapat bahwa masyarakat masih terbuai dengan konstruksi kesejahteraan Orde Baru yang dibentuk pada rezim Soeharto. Pada waktu itu, media- media cenderung memperlihatkan keberhasilan-keberhasilan pemerintah dalam membangun struktur ekonomi. Citra positif terhadap pembangunan ekonomi sekaligus penjaga kestabilan kehidupan sosial pun terbentuk. Akibatnya, banyak orang cenderung lebih memilih kembali hidup pada masa Orde Baru dibandingkan menjalani kehidupan di masa kini. Apalagi keadaan sekarang diperparah dengan janji reformasi yang gagal menampilkan citra yang lebih baik.

Hal di atas sangat kentara jika kita lebih dalam lagi mengkaji senyum-senyum itu. Pada setiap poster yang dipasang, pesan yang disampaikan cenderung seragam, yaitu kritik atas kondisi ekonomi saat ini. Sebagai contoh, seperti: "Piye kabare le., wis mangan durung.... Beras saiki piro... Luwih penak jamanku to?" atau ungkapan seperti ini: "Piye kabare., Bensin mundak yo.... ijih murah jamanku to?". Narasi-narasi yang disampaikan dalam gambar-gambar itu sudah pasti tidak lepas menggunakan sapaan khas gaya jawa kemudian dibagian akhir memperbandingkan kondisi sosial saat ini dengan kondisi di jaman Orde Baru. Dua hal itulah yang menjadi inti dari semua pesan yang ingin disampaikan.

Teks Soeharto dengan gambar Soeharto juga tidak akan "bunyi" tanpa kata- kata di sampingnya. Pilihan kata dengan bahasa Jawa digabung bahasa gaul anak muda sekarang, menunjukkan si pembuat hendak membangkitkan Soeharto untuk menghadapi situasi sekarang. Frase "piye kabare" juga "piye kabare le...." menurut peneliti dibentuk untuk menghadirkan sosok Soeharto yang seakan-akan sudah akrab dan dekat dengan masyarakat. Sapaan tersebut dalam pergaulan masyarakat Yogyakarta juga sering digunakan untuk menunjukkan kedekatan emosional antara sesama kawan. Kedekatan tersebutlah yang ingin dicapai 
dengan teks tersebut. Apalagi penambahan kata "le...." secara eksplisit mengkonstruksikan sosok Soeharto sebagai seorang bapak. Dalam budaya Jawa yang sangat patriarkis, sosok bapak adalah segalanya. Sosok ini dipandang sebagai representasi kekuasaan, pengayom, dan karakter-karakter lain yang menunjukkan superioritas seorang patriarki (Mulder, 1978).

Lebih lanjut yaitu kalimat "Luwih penak jamanku" menggambarkan rasa frustrasi masyarakat atas keadaan yang cenderung tidak berubah dari waktu ke waktu. Kalimat itu menjadi pelampiasan kepada pemerintah karena seakan-akan mereka tidak cakap mengerjakan amanat reformasi (Selian \& Melina, 2018). Kalimat itu juga seakan menjadi ungkapan penyesalan masyarakat karena turut menggulingkan, mengolok-olok, juga menyumpah serapahi Soeharto dan pemerintahan Orde Barunya.

\section{Simpulan}

Secara garis besar, dalam penelitian ini dapat ditarik simpulan. Setelah dilakukan penginterpretasian makna atas munculnya teks bersimbol Soeharto di Era Demokrasi saat ini, fenomena ini dilatarbelakangi oleh berbagai motif yang mengatasnamakan kerinduan rakyat pada Era Soeharto, yakni: motif ekonomi, motif politik, motif sosial, motif moralitas, motif humor, dan motif iklan (propaganda) berupa pemberitahuan maupun ajakan, motif penunjukan identitas diri dan motivasi kritikan untuk kehidupan yang lebih baik. Selain itu juga terdapat praktik politik khususnya pada proses diadakannya pemilu. Pemilu sangat butuh adanya ruang-ruang kontestasi dalam bentuk apapun, asalkan tujuan tersebut tercapai dan masyarakat dapat membenarkan kekuasaan tersebut.

Adapun simpulan mengenai empat analisis dialogis historikalitas teori Hermeneutika Gadamer yang ditemukan peneliti pada kajian ini, diantaranya: Pertama, bildung atau pembentukan jalan pikiran, orang tidak dapat menginterpretasi ilmu-ilmu tersebut dengan caranya sendiri. Kedua, Sensus Communis atau pertimbangan praktis yang baik atau pandangan yang mendasari komunitas. Ketiga, pertimbangan, yaitu menggolongkan hal-hal yang khusus atas dasar pandangan tentang yang universal. Keempat, taste atau selera, yaitu sikap subjektif yang berhubungan dengan macam-macam rasa atau keseimbangan antara insting panca indera dan kebebasan intelektual.

Adapun proposisi yang ditemukan peneliti pada kajian ini yaitu dari empat konsep yang dikemukakan oleh Gadamer diatas, telah cukup memberikan kesadaran kepada kita bahwa hermeneutika adalah konsep pembaruan terhadap nilai-nilai dasar yang memiliki dialektika historis dalam hubungannya dengan nilainilai dasar manusia. Oleh sebab itu dalam menggunakan keempat analisis Gadamer harus ada pengalaman historis dari interpretator bukan sebuah dogma dalam konteks kejayaan Orde Baru. Misalnya menggambarkan adanya pengakuan bahwa manusia memiliki kemampuan untuk memahami teks-teks di luar dirinya, tanpa menghilangkan eksistensi teks tersebut. Fungsinya tidak lain hanyalah manusia harus mampu berdialektika dengan perubahan demi kemaslahatan manusia itu sendiri. Karena manusia adalah mahluk yang dinamis dan mencintai perubahan.

\section{Daftar Pustaka}

Abdulgani-Knapp R (2007) Soeharto: The Life and Legacy of Indonesia's Second President. Singapore: Marshall Cavendish Editions.

Adityawan A. (2008). Propaganda Pemimpin Politik Indonesia. Jakarta: LP3S.

Anderson BROG (1972) The Idea of Power in Javanese Culture in C. Rolt (Ed.) Culture and Politics in Indonesia. Ithaca: Cornell University Press. 
Anderson BROG (1996) Bahasa Politik Indonesia. Dalam: Latif Y dan Idi SI (editor). Bahasa dan Kekuasaan: Politik Teks di Panggung Orde Baru. Bandung: Mizan.

Anderson B (2007) The Idea of Power in Javanese Culture dalam buku Culture and Politics in Indonesia (ed) Claire Holt. Jakarta: Equinox Publishing

Ashrianto PD (2016) Analisis semiotika film Janur Kuning sebagai representasi ideologi kekuasaan Soeharto. Nirmana 16 (1):1-11.

Bleicher J (2007) Hermeneutika Kontemporer. Penerjemah Khoiri, Imam. Yogyakarta: Fajar Pustaka.

Davey N (2012) Unquiet understanding: Gadamer's philosophical hermeneutics. Suny Press.

Elson RE (2001) Suharto, A Political Biography. Cambridge University Press.

Gadamer, H. G. (1975). Hermeneutics and social science. Cultural hermeneutics, 2(4), 307-316.

Gadamer HG (2004) Kebenaran dan Metode: Pengantar Filsafat Hermeneutika Penerjemah Sahidah, Ahmad dari judul asli Truth and Method. Yogyakarta: Pustaka Pelajar.

Heryanto A (1993) Discourse and State-Terrorism: A Case Study of Political Trials in New Order Indonesia 1989-1990. A Thesis Submitted for the Degree of Doctor of Philosophy in the Department of Anthropology Monash University Australia.

Holt C (Ed.) (2007). Culture and politics in Indonesia. Equinox Publishing.

JK, Belinda, Lestari, Mayang \& Alfan M (2014) Piye Kabare...? Penak Jamanku to!. Damian Press.

Muzir IR (2006) Hermeneutika Filosofis: Hans Georg Gadamer. Yogyakarta: Ar-Ruzz Media.

Mulder N (1978) Mysticism and Everyday Life in Contemporary Java: Cultural Persistence and Change. Singapura: Singapore University Press.

Palmer RE (2005) Hermeneutika: Teori Baru Mengenai Interpretasi. Penerjemah. Musnur Hery dan Damanhuri Muhammed. Yogyakarta: Pustaka Pelajar.

Piliang YA \& Sihombing RM (2016). Figure replication in Soeharto visual meme. Jurnal Sosioteknologi $15(1): 32-40$.

Poloma M (2004) Sosiologi Kontemporer. Jakarta: PT. Raja Grafindo Persada.

Purnaweni H (2004) Demokrasi Indonesia: Dari masa ke masa. Jurnal Administrasi Publik 3 (2).

Ritzer, George dan Doulas JG (2005) Teori Sosial Modern. Jakarta: Kencana.

Salim A (2006) Teori dan Paradigma Penelitian Sosial: Buku Sumber Untuk Penelitian Kualitatif. Yogyakarta: Tiara Teks.

Selian DL \& Melina C (2018) Kebebasan Berekspresi di Era Demokrasi: Catatan Penegakan Hak Asasi Manusia. Lex Scientia Law Review 2 (2):185-194.

Sparinga DT (1997) Discourse, Democracy, and Intelectuals in New Order Indonesia. (Disertasi Flinders University). Dalam: Yulianto, Andik. Kekuasaan Soeharto dan Simbol-simbolnya (Telaah Kekuasaan Soehrto dan Simbol- simbolnya dalam Teks Kumpulan Cerpen Soeharto dalam Cerpen Indonesia). Tesis Universitas Airlangga. Surabaya.

Sumartono W (2013) Gimana Kabarmu, Nak, Masih Enak Jamanku, Tho?. Jogjakarta: Palapa.

Wadipalapa RP (2015) Meme culture \& komedi-satire politik: kontestasi pemilihan presiden dalam media baru. Jurnal Ilmu Komunikasi 12 (1):1-18.

Wardaya FBT (2007) Menguak misteri kekuasaan Soeharto. Galangpress Group.

Widjojo MS \& Noorsalim M. (Eds.) (2004) Bahasa Negara Versus Bahasa Gerakan Mahasiswa: Kajian Semiotik atas Teks-Teks Pidato Presiden Soeharto dan Selebaran Gerakan Mahasiswa. Yayasan Obor Indonesia.

Van Langenberg M (1986) Analysing Indonesia's New Order State: A keywords Approach. Review of Indonesian and Malaysian Affairs 20 (2):1-47. 